\title{
ASO Visual Abstract: Nipple-Sparing Mastectomy_Are We Providing Proper Prophylactic Antibiotic Coverage?
}

\author{
Ayat ElSherif, MD ${ }^{\mathbf{1}}$, Daniela Cocco, $\mathrm{MD}^{\mathbf{1}}$, Sherif Armanyous, $\mathrm{MD}^{\mathbf{1}}$, Andi Cummins, $\mathrm{MD}^{\mathbf{2}}$, \\ Kristina Shaffer, MD ${ }^{1}$, Eliana F. R. Duraes, $\mathbf{M D}^{2}$, Steven Bernard, $\mathbf{M D}^{2}$, Risal Djohan, $\mathbf{M D}^{2}$, \\ Graham Schwarz, $\mathrm{MD}^{2}$, Chao Tu, $\mathrm{MS}^{3}$, and Stephanie A. Valente, $\mathrm{DO}^{1,4}{ }^{10}$ \\ ${ }^{1}$ Division of Breast Services, Department of Breast Surgery, Cleveland Clinic, Cleveland, OH; ${ }^{2}$ Department of Plastic and \\ Reconstructive Surgery, Cleveland Clinic, Cleveland, $\mathrm{OH} ;{ }^{3}$ Department of Quantitative Health, Cleveland Clinic, \\ Cleveland, OH; ${ }^{4}$ Division of Breast Services, Department of General Surgery, Cleveland Clinic, Cleveland, OH
}

Perioperative antibiotic regimens, incidence and bacteriology of surgical site infections in nipple-sparing mastectomy with implant-based reconstruction were assessed (https://doi.org/10.1245/s10434-021-10449-
5). Use of broader antibiotic coverage was not associated with improved outcomes. Patient and treatment factors predicted surgical site infections rather than prophylactic antibiotic regimens.

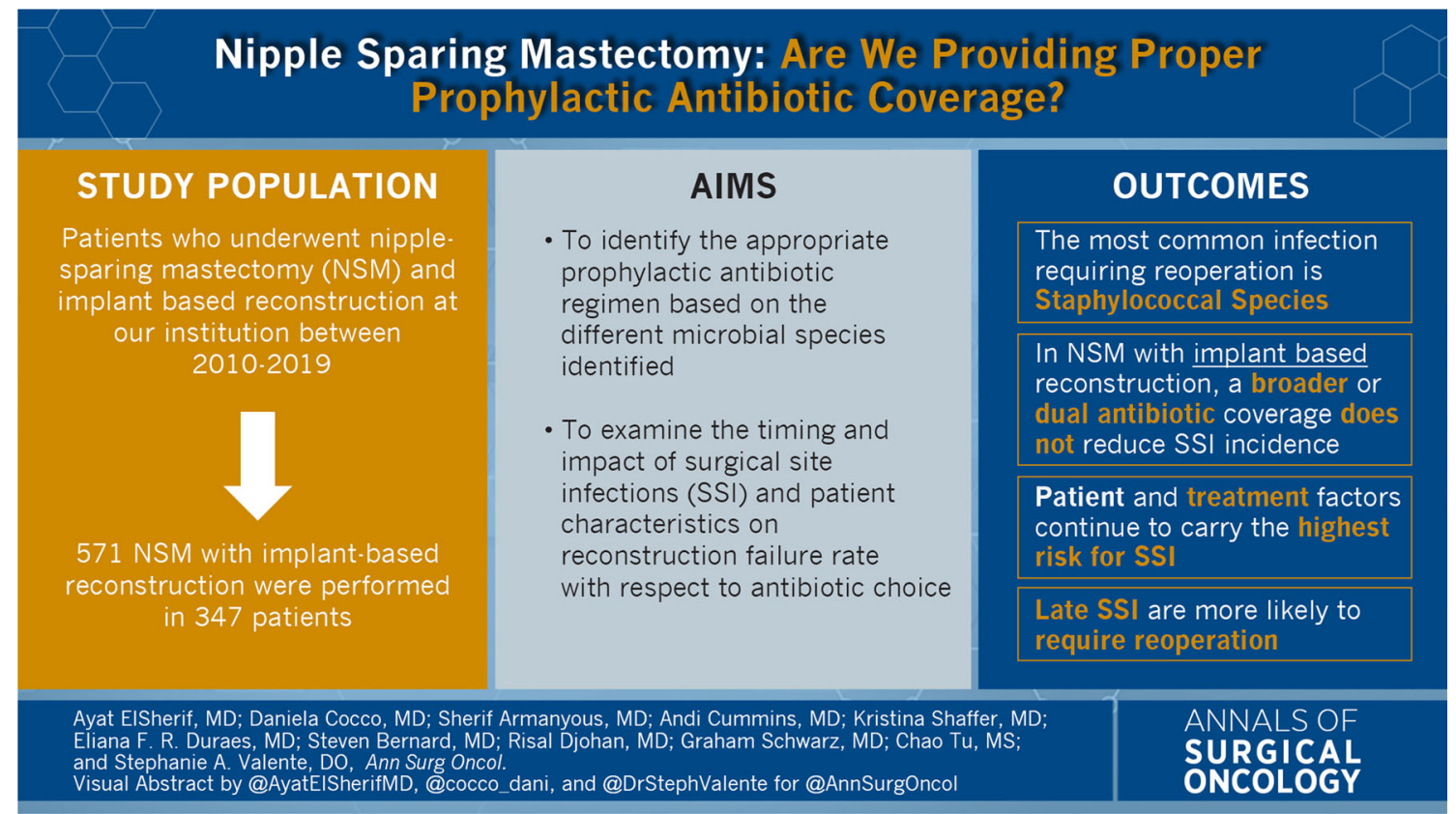

(C) Society of Surgical Oncology 2021

Published Online: 14 August 2021

S. A. Valente, DO

e-mail: Valents3@ccf.org
Publisher's Note Springer Nature remains neutral with regard to jurisdictional claims in published maps and institutional affiliations. 